\title{
Improved Method for Injecting Fungal Inoculum into Corn Ears
}

\author{
N. R. Anderson, J. D. Ravellette, and K. A. Wise, Department of Botany and Plant Pathology, Purdue University, West Lafayette, IN 47905
}

Accepted for publication 25 June 2016. Published 21 July 2016.

\section{ABSTRACT}

Anderson, N. R., Ravellette, J. D., and Wise, K. A. 2016. Improved method for injecting fungal inoculum into corn ears. Plant Health Prog. 17:163-166.

Corn (Zea mays L.) ear rot pathogens reduce yield and grain quality annually, and research on these pathogens and their interactions with the host can require inoculation of fungal material into the ears. A new system of mechanically inoculating corn ears was designed using a hydration backpack and auto-filling vaccinator with a needle attached. The efficiency of the new system was compared to a previously established inoculation method using a manual syringe method with an 18 -gauge blunt end needle attached to a $60-\mathrm{ml}$ syringe, with inoculum carried in a plastic beaker. Inoculation methods were tested by comparing the time to inoculate 100 corn ears with separate conidial suspensions of Fusarium verticillioides and $F$. graminearum in a replicated field trial. The new mechanical inoculation system reduced inoculation time by $42 \%$ $(P=0.0015)$ when compared to the manual syringe and needle method. Additional benefits of the new method include reduced risk of inoculum contamination, consistent inoculum volume per ear, and increased safety for personnel doing the inoculations.

\section{IMPORTANCE OF EAR ROT RESEARCH}

Corn (Zea mays L.) ear rot diseases result in several hundred millions bushels of lost yield every year in the United States (Mueller and Wise 2014). This yield loss is compounded by the ability of some ear rot fungi to produce mycotoxins, which adversely affect grain quality and marketability. Some of these pathogens include Aspergillus flavus (Link), Fusarium graminearum (Schwabe), F. verticilliodes (Sacc.), and Stenocarpella maydis (Berk.). The associated mycotoxins aflatoxin, deoxynivalenol, fumonisin, and diplodiatoxin, respectively, can cause significant health effects when ingested by animals and humans (Gelderblom et al. 1988; IARC 1993; Richard 2007).

Field-based research on these ear rot fungi aims to understand fungal infection mechanisms, isolate variability or differentiation, and the factors affecting mycotoxin production in grain, to name a few (Gendloff et al. 1986; Pope and McCarter 1992; Reid et al. 1996; Reid and Sinha 1998; Steyn et al. 1972; Vigier et al. 2001). Screening germplasm or commercial hybrids for ear rot resistance is also common; as is research to better manage diseases caused by ear rot fungi (Afolabi et al. 2007; Presello et al. 2005; Reid et al. 1993; Robertson et al. 2005; Sutton and Beliko 1981). Many of these fungi infect through natural openings in the corn plant or wounds caused by insects or adverse environmental conditions, or by fungal transportation through the silk channels (Koehler 1942). Therefore, research to examine isolate variability, mycotoxin production, and germplasm resistance often involves introducing inoculum to corn plants at a susceptible growth stage. Standard inoculation methods include spreading colonized grain over the soil surface of the research area, spraying a conidial suspension over the top of the plants, wounding plants or ears and then introducing inoculum to the injury site, or directly injecting fungal material into silk channels (Fig. 1) (Boling et al. 1969;

Corresponding author: K. A. Wise. Email: kawise@purdue.edu.
Chungu et al. 1996; Clements et al. 2003; Drepper and Renfro 1990; King and Scott 1982; Schaafsma et al. 1997; Mario et al. 2011). Inoculating with grain inoculum or spraying conidial suspensions over plants simulates natural infection, but can result in inconsistent disease levels across different environments. Wound injection methods (Gulya et al. 1980; Chungu et al. 1996) can be time consuming, cause unintended destruction to the plant, and require considerable practice to ensure consistent inoculum delivery. Silk channel injections provide a consistent and reproducible way to get fungal inoculum into the ear. Several studies have evaluated the effectiveness of inoculation methods, including Clements et al. 2003, that suggested that an injection technique was the most suitable for producing the desired disease severity. This information led us to develop a simple, selfcontained fungal injection system, which improves upon current

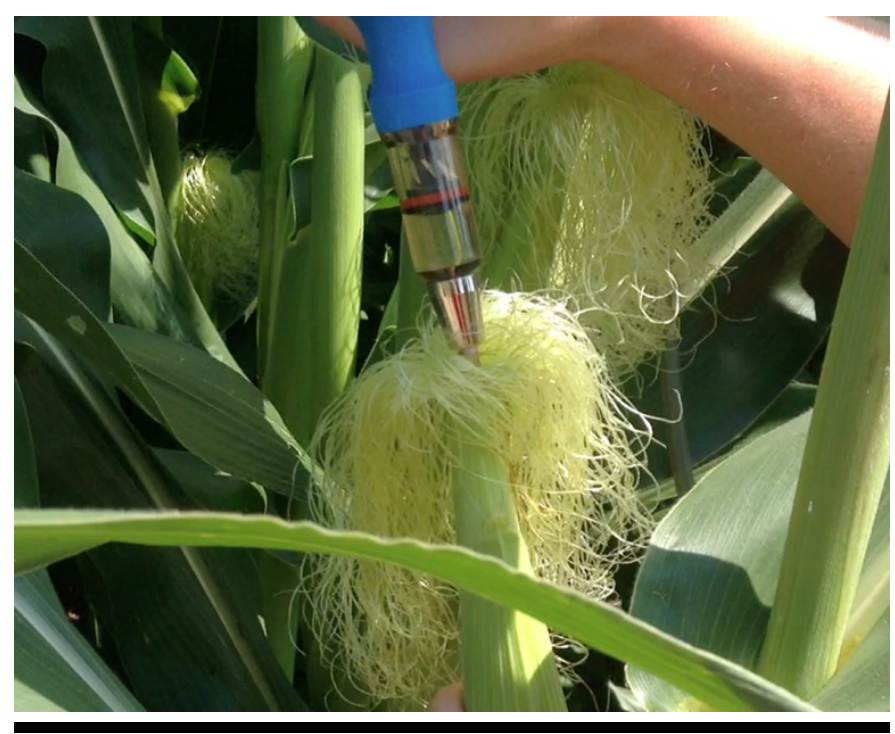

FIGURE 1

Injecting a corn ear at silking stage (R1) using the AllFlex syringe. 
silk channel inoculation methods by reducing inoculation time. This time savings is critical for researchers conducting multiple trials or large trials, such as hybrid or germplasm resistance screenings.

\section{DESIGN OF INOCULUM DELIVERY SYSTEM}

The new system consists of a hydration backpack connected to a 5-ml, tube-fed, auto-filling syringe (5EM, AllFlex, Dallas, TX; Fig. 2). The inoculum container is a 2-liter hydration backpack (Outdoor Products, Los Angeles, CA; Fig. 3) with the bite valve removed, leaving an open-ended hose. The syringe hose and bladder hose are not of the same diameter; therefore, the two pieces are connected using a $1 / 4$-inch $(6.35-\mathrm{mm})$ outside diameter $\times 1 / 4$-inch male pipe thread compression fitting attached to the syringe hose, a $1 / 2$-inch $(12.7-\mathrm{mm})$ outside diameter $\times 1 / 4$-inch male pipe thread compression fitting attached to the bladder hose, with the two fittings connected together using a $1 / 4$-inch female pipe thread $\times 1 / 4$-inch female pipe thread coupler (Fig. 4). Teflon tape was used on the connections between the compression fittings and coupler to prevent leakage. Brass compression fittings were used for their durability and because they will not rust when exposed to moisture.

The auto-filling syringe can be adjusted to deliver 1 to $5 \mathrm{ml}$, and is easily disassembled for routine cleaning or changing

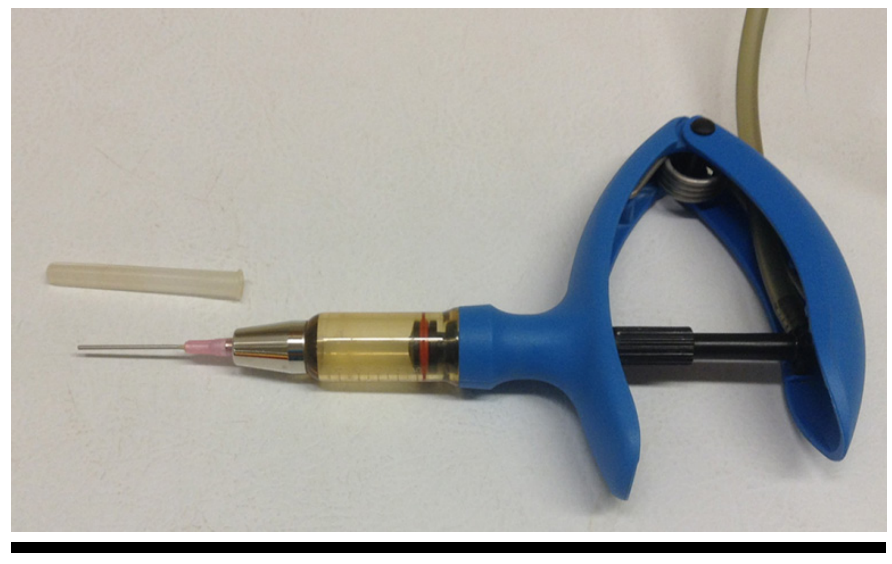

FIGURE 2

AllFlex syringe with an 18-gauge blunt-end needle attached.

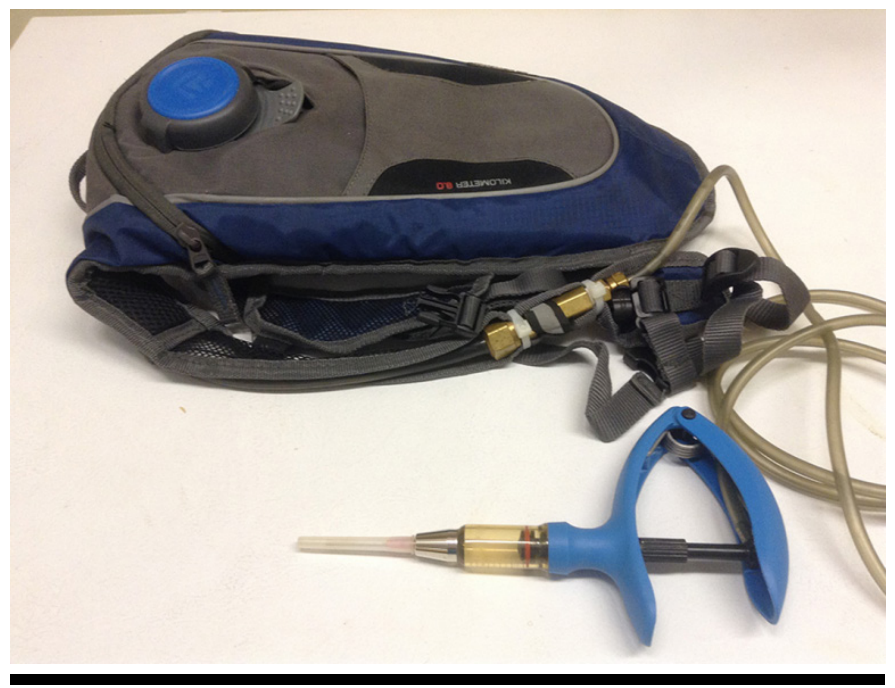

FIGURE 3

Completed assembly of AllFlex syringe attached to hydration backpack. inoculum between treatments. A blunt-end, 18-gauge, 3.8-cmlong needle (Figs. 2, 3, and 4) (Beckton, Dickinson \& Co., Franklin Lakes, NJ) is attached to the end of the syringe (Figs. 2 and 5).

\section{INOCULUM PREPARATION AND EXPERIMENTAL ARRANGEMENT}

Efficacy of the new mechanical syringe injection system was tested at the Purdue Agronomy Center for Research and Education near West Lafayette, IN. The experiment was designed as a randomized complete block with two replications.

One isolate of $F$. graminearum and one isolate of $F$. verticillioides originally collected in Indiana in 2013 were removed from long-term $20 \%$ glycerol stocks and transferred onto potato dextrose agar (PDA; Beckton, Dickinson \& Co.). After 10 days of $10 \mathrm{~h}$ light and $14 \mathrm{~h}$ dark cycles at $22.2^{\circ} \mathrm{C}, 5 \mathrm{ml}$ of sterile water was added to the $F$. verticillioides plates, and fungal growth was removed and placed in suspension. F. graminearum isolates were removed from long-term storage and grown for 5 days under $10 \mathrm{~h}$ light and $14 \mathrm{~h}$ dark cycles at $23^{\circ} \mathrm{C}$, and then a small plug $3 \mathrm{~mm} \times$ $3 \mathrm{~mm}$ was used to inoculate flasks of mung bean broth (Bai and Shaner 1996). After 10 days on an orbital shaker at $110 \mathrm{rpm}$ under $10 \mathrm{~h}$ light and $14 \mathrm{~h}$ dark cycles at $22.2^{\circ} \mathrm{C}$, the suspension was filtered through 2 layers of cheesecloth.

Conidia in both resulting suspensions were quantified using a hemocytometer and suspensions were adjusted to a concentration of 20,000 conidia per $\mathrm{ml}$ for $F$. graminearum and 200,000 conidia per $\mathrm{ml}$ for $F$. verticillioides.

Two hybrids were used in the experiment. Pioneer P32T82 was inoculated with $F$. graminearum and Pioneer P1339AM1 was

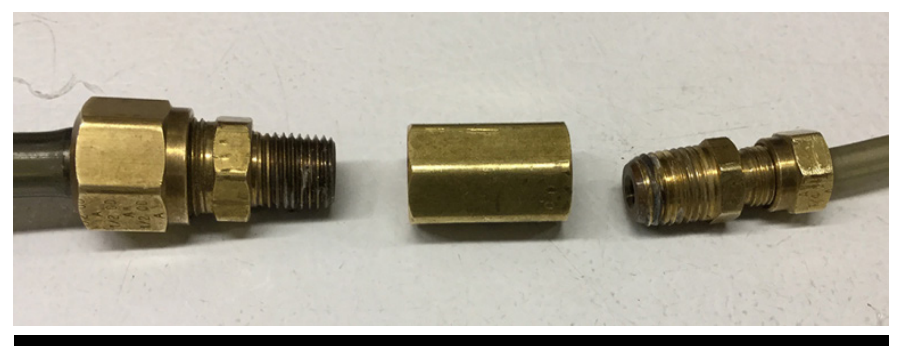

FIGURE 4

Brass airline compression fittings and coupler used to connect backpack hose to syringe hose.

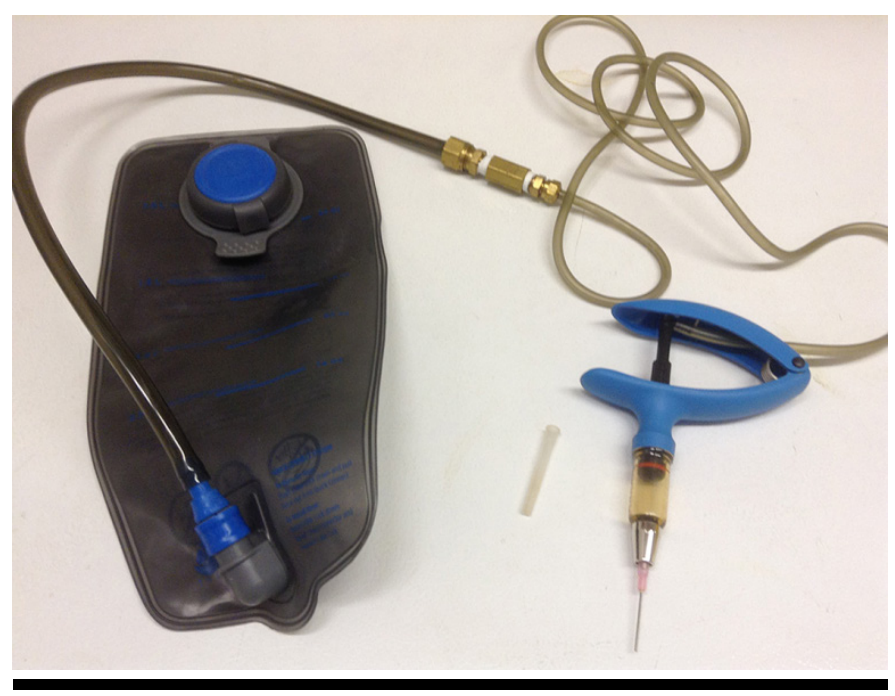

FIGURE 5

AllFlex syringe attached to a hydration bladder. 
inoculated with $F$. verticillioides. Both hybrids were planted on 7 May 2014 at a rate of 79,070 seeds per hectare $(0.76-\mathrm{m}$ row spacing). Plots consisted of single rows $15.24 \mathrm{~m}$ long, containing 100 plants. Hybrids were selected based on their susceptibility to the given pathogen. When corn reached silking (growth stage R1; Abendroth et al. 2011), the conidial suspension was either injected using the manual syringe injection method, or using the new mechanical syringe injection method. The manual syringe method consisted of using an 18-gauge blunt-end needle (Beckton, Dickinson \& Co.) attached to a 60-ml syringe (Beckton, Dickinson \& Co.). To carry inoculum, approximately 1 liter of inoculum was poured into a 1-liter plastic beaker (Nalge Nunc Intl. Corp., Rochester NY) and carried through the plots. Each fungal conidial suspension was injected into 100 corn ears in a single row at a rate of $5 \mathrm{ml}$ per ear, with a row serving as an experimental unit. Time to inoculate 100 ears was measured using a digital stopwatch beginning when the needle injection occurred in the first ear to when the needle was removed from the last ear in the row. Each injection method was replicated twice for each fungal isolate.

\section{COMPARISON OF INOCULUM DELIVERY SYSTEMS}

The impact of method of inoculum delivery, type of fungal inoculum, and their interaction were analyzed using PROC GLIMMIX in SAS v. 9.4 (SAS Institute Inc., Cary, NC). Replication was treated as a random effect. No interaction effect of inoculum delivery system and type of inoculum was observed $(P=0.4517)$. Fungal species inoculum ( $F$. graminearum vs. $F$. verticillioides) did not impact time to complete inoculation $(P=0.2752)$. Time to complete inoculation was significantly reduced when using the new mechanical syringe inoculum delivery system compared to the manual filling needle injection $(P=0.0015)$. Inoculation times per experimental unit (100 ears) totaled 5.4 min with the mechanical syringe injection method, compared to $9.2 \mathrm{~min}$ with the manual needle injection method. This represented a $42 \%$ reduction in the amount of time needed to inoculate plots with the mechanical syringe injection method. Visual inspection of disease incidence of at least 10 ears occurred in each inoculated plot at the dent stage (R5). Visual ratings indicated that both inoculum delivery methods resulted in $100 \%$ disease incidence and the desired ear rot for each ear inspected.

\section{ADVANTAGES OF A NEW INOCULUM DELIVERY SYSTEM}

Our inoculum delivery system provides an advantage for inoculating field-scale research trials aimed at examining the impact of ear rot pathogens in corn. This method was significantly faster than another standard inoculation method using manual needle injections. The time savings observed is likely due to the ability to consistently and repeatedly inject inoculum across a plot or experimental unit without having to load syringes with inoculum every 5 to 6 plants. Additionally, carrying up to 2 liters of inoculum hands-free reduced the time spent refilling inoculum delivery containers. This time saved can be especially useful when doing multiple trials or large trials, such as hybrid or germplasm resistance screenings.

To our knowledge, this is the first detailed description of an inoculation method using a self-contained backpack and autofilling injection system for inoculum delivery to corn ears. One previous research publication utilized a closed inoculum delivery system with a calibrated spray gun and backpack to carry the inoculum to infect corn with Ustilago maydis to produce huitlacoche (Valverde et al. 1993). However, this system needs to be pressurized to function properly, and requires a large and bulky backpack that can make it difficult to move through a cornfield at growth stage R1 without causing unintended injury to plants. Another closed inoculation system was mentioned in Reid et al. (1996), and was composed of a vaccine inoculator and backpack container (Nasco, Fort Atkinson, WI); however, specific details of the inoculation system were not provided to allow comparison between this system and our mechanical syringe injection system.

Hydration backpacks are primarily used for carrying potable liquids on a person while engaging in physical activity. This makes them a well-suited transport vessel for an inoculum delivery system (Fig. 6). These backpacks come in multiple sizes, and do not need to be limited to 2 liters, as was used in our system. However, when using larger bladders, conidial suspension settling and the impact of sun or heat exposure on inoculum should be considered.

The syringe type and size may also be adjusted to suit specific pathogen inoculation systems. With a 2-liter backpack, typically 300 or more $5-\mathrm{ml}$ injections can occur from a single backpack filled with inoculum. An added benefit of using the auto-filling syringe is that each injection was precisely measured, whereas when using a manual syringe the final volume of each injection is subject to the accuracy of the individual doing the inoculating. du Toit and Pataky (1999) demonstrated that when inoculating sweet corn in the field with $U$. maydis, smut levels varied more due to user inexperience than to differences in inoculum concentration. They reported that disease incidence and severity were reduced in treatments where inexperienced workers inoculated plots compared to treatments inoculated by more experienced personnel, and that experience level had a greater effect on disease severity than inoculum concentration. Therefore, the need to deliver inoculum consistently and accurately is important to obtaining accurate research results, and the mechanical syringe injection method described here has proven to help with this process.

In our system, the hose from the bladder is of larger diameter than the hose from the syringe, which helps with feeding the liquid from the backpack into the syringe, resulting in fewer misfeeds (incorrect amount of inoculum delivered to the syringe) and less air introduced into the system. The needle we used was a blunt end 18-gauge needle, which worked best for silk channel inoculations. Anecdotal evidence from previous inoculations indicated that a larger needle (14 gauge) plugged more frequently with silk tissue and a smaller needle (20 gauge) plugged less often

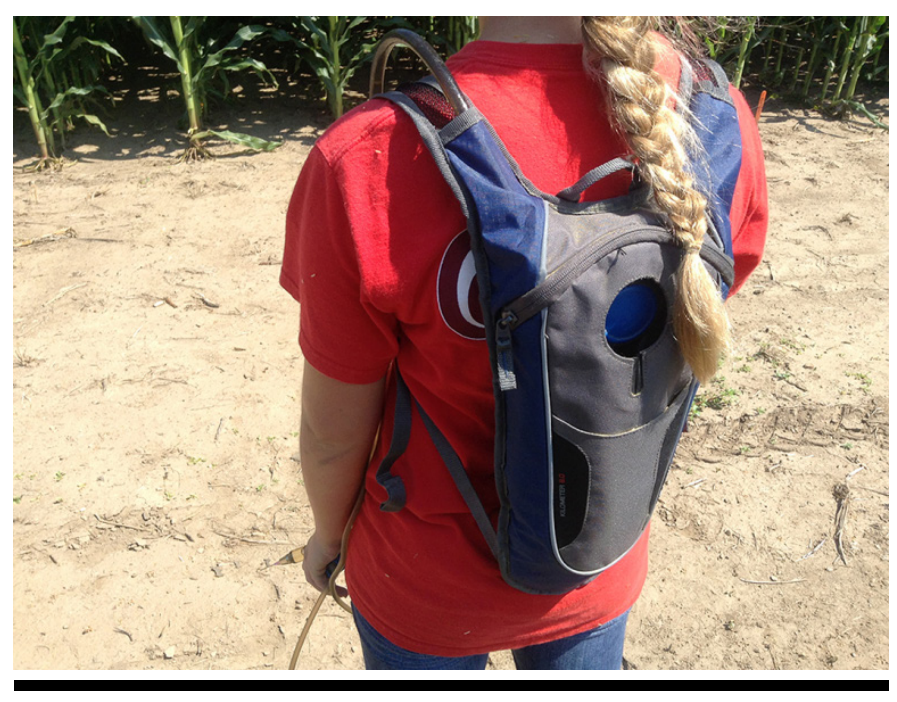

FIGURE 6

Person wearing the mechanical syringe injection system. 
but required more force and time to inject the entire 5-ml suspension. A blunt-end needle was also chosen for the system to reduce the risk of potential puncture injuries to those doing the inoculations.

The closed system of the bladder connected to the syringe reduces the likelihood of contamination by debris, soil, or other pathogens, because the inoculum is not exposed to the environment and reduces any loss due to spillage.

Overall, our new mechanical syringe injection system improves the speed and efficiency of direct silk channel inoculations. Additional benefits include reduced risk of inoculum contamination, consistent inoculum volume per ear, and increased safety for personnel doing the inoculations.

\section{ACKNOWLEDGMENTS}

We thank Corey Gerber, Kaitlin Lewis, Marianna Kastberg-Leonard, Gaelle Hollandbeck, and Martha Patricia Romero Luna for assisting with the development of this method.

\section{LITERATURE CITED}

Abendroth, L. J., Elmore, R. W., Boyer, M. J., and Marlay, S. K. 2011. Corn Growth and Development. Ext. Pub. PMR 1009. Iowa State Univ., Ames.

Afolabi, C. G., Ojiambo, P. S., Ekpo, E. J. A., Menkir, A., and Bandyopadhyay, R. 2007. Evaluation of maize inbred lines for resistance to Fusarium ear rot and fumonisin accumulation in grain in tropical Africa. Phytopathology 91:279-286.

Bai, G. H., and Shaner, G. 1996. Variation in Fusarium graminearum and cultivar resistance to wheat scab. Plant Dis. 80:975-979.

Boling, M. B., Grogan, C. O., and Broyles, W. 1969. A new method of artificially producing epiphytotics of Fusarium ear rot of maize. Plant Dis. 47:315-317.

Chungu, C., Mather, D. E., and Ried, L. M., and Hamilton, R. I. 1996. Comparison of techniques for inoculating maize silk, kernel, and cob tissues with Fusarium graminearum. Plant Dis. 80:81-84.

Clements, M. J., Kleinschmidt, C. E., Maragos, C. M., and Pataky, J. K., and White, D. G. 2003. Evaluation of inoculation techniques for Fusarium ear rot and fumonisin contamination of corn. Plant Dis. 87:147-153.

Drepper, W. J., and Renfro, B. L. 1990. Comparison of methods of inoculation of ears and stalks of maize with Fusarium moniliform. Plant Dis. 74:952956.

du Toit, L. J., and Pataky, J. K. 1999. Variation associated with silk channel inoculation for common smut of sweet corn. Plant Dis. 83:727-732.

Gelderblom, W. C. A., Jaskiewicz, K., Marasas, W. F. O., Thiel, P. G., Vleggar, M. J., and Kriek, N. P. J. 1988. Fumonisins-novel mycotoxins with cancer promoting activity produced by Fusarium moniliforme. Appl. Environ. Microbiol. 54:1806-1811.
Gendloff, E. H., Rossman, E. C., Casale, W. L., Isleib, T. G., and Hart. L. P. 1986. Components of resistance to Fusarium ear rot in field corn. Phytopathology 76:684-688.

Gulya, T. J., Jr., Martinson, C. A., and Loesch, P. J., Jr. 1980. Evaluation of inoculation techniques and rating dates for Fusarium ear rot of opaque-2 maize. Phytopathology 70:1116-1118.

IARC (International Agency for Research on Cancer). 1993. Some naturally occurring substances: Food items and constituents. Heterocyclic aromatic amines and mycotoxins. IARC Monogr. Eval. Carcinog. Risks Hum. 56.

King, S. B., and Scott, G. E. 1982. Field inoculation techniques to evaluate maize for reaction to kernel infection by Aspergillus flavus. Phytopathology 72:782-785.

Koehler, B. 1942. Natural mode of entrance of fungi into corn ears and some symptoms that indicate infection. J. Agric. Res. 64:421-442.

Mario, J. L., Reis, E. M., and Juliatti, F. C. 2011. Three inoculation methods for screening corn germplasm to white ear rot resistance. Trop. Plant Pathol. 36:362-366.

Mueller, D. S., and Wise, K. A. 2014. Diseases of Corn: Corn Disease Loss Estimates From the United States and Ontario, Canada - 2014. Ext. Pub. BP-96-13-W. Purdue Univ., West Lafayette, IN.

Pope, D. D., and McCarter, S. M. 1992. Evaluation of inoculation methods for inducing smut on corn ears. Phytopathology 82:950-955.

Presello, D. A., Reid, L. M., Butler, G., and Mather, D. E. 2005. Pedigree selection for Gibberella ear rot resistance in maize. Euphytica 143:1-8.

Valverde, M. E., Fallah Moghaddam, P., Zavala-Gallardo, M. S., Pataky, J. K., Paredes-Lopez O., and Pederson, W. L. 1993. Yield and quality of huitlacoche on sweet corn inoculated with Ustilago maydis. J. Am. Soc. Hortic. Sci.. 28:782-785.

Reid, L. M., Mather, D. E., and Hamilton, R. I. 1996. Distribution of deoxynivalenol in Fusarium graminearum-infected maize ears. Phytopathology 86:110-114.

Reid, L. M. and Sinha, R. C. 1998. Maize maturity and the development of Gibberella ear rot symptoms and deoxynivalenol after inoculation. Eur. J. Plant Pathol. 104:147-154.

Reid, L. M., Spaner, D., Mather, D. E., Bolton, A. T., and Hamilton, R. I. 1993. Resistance of maize hybrids and inbreds following silk inoculation with three isolates of Fusarium graminearum. Plant Dis. 77:11248-1251.

Richard, J. L. 2007. Some major mycotoxins and their mycotoxicoses: An overview. Int. J. Food Microbiol. 119:3-10.

Robertson, L. A., Kleinschmidt, C. E., White, D. G., Payne, G. A., Maragos, C. M., and Holland, J. B. 2005. Heritablilities and correlations of Fusarium ear rot resistance and fumonisin contamination resistance in two maize populations. Crop Sci. 46:353-361.

Schaafsma, A. W., Nicol, R. W., and Reid, L. M. 1997. Evaluating commercial maize hybrids for resistance to Gibberella ear rot. Eur. J. Plant Pathol.103:737-746.

Steyn, P. S., Wessels, P. L., and Holzapfel, C. W. 1972. The isolation of a toxic metabolite from Diplodia maydis (Berk.) Sacc. Tetrahedon 28:4775-4785.

Sutton, J. C., and Beliko, W. 1981. Methods for quantifying partial resistance to Gibberella zeae in maize ears. Can. J. Plant Pathol. 3:26-32.

Vigier, B., Reid, L. M., Dwyer, L. M., Stewart, D. W., Sinha, R. C., Arnason, J. T., and Butler, G. 2001. Maize resistance to Gibberella ear rot: Symptoms, deoxynivalenol, and yield. Can. J. Plant Pathol. 23:99-105. 